\title{
BMJ Open Lung protective ventilation in patients undergoing major surgery: a systematic review incorporating a Bayesian approach
}

\author{
Zhongheng Zhang, ${ }^{1}$ Xiaoyun $\mathrm{Hu},{ }^{2}$ Xia Zhang, ${ }^{1}$ Xiuqi Zhu, ${ }^{1}$ Liqian Chen, ${ }^{3}$ Li Zhu, ${ }^{1}$ \\ Caibao Hu, ${ }^{4}$ Bin Du, ${ }^{2}$ for China Critical Care Clinical Trials Group (CCCCTG)
}

To cite: Zhang Z, Hu X, Zhang $X$, et al. Lung protective ventilation in patients undergoing major surgery: a systematic review incorporating a Bayesian approach. BMJ Open 2015;5: e007473. doi:10.1136/ bmjopen-2014-007473

- Prepublication history and additional material is available. To view please visit the journal (http://dx.doi.org/ 10.1136/bmjopen-2014007473).

Received 16 December 2014 Revised 2 July 2015 Accepted 4 August 2015

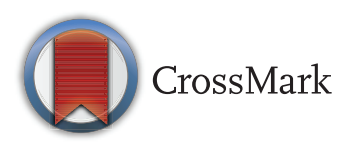

For numbered affiliations see end of article.

Correspondence to

Dr Bin Du;

dubin98@gmail.com

\section{ABSTRACT}

Objective: Protective ventilation (PV) has been validated in patients with acute respiratory distress syndrome. However, the effect of PV in patients undergoing major surgery is controversial. The study aimed to explore the beneficial effect of PV on patients undergoing a major operation by systematic review and meta-analysis.

Setting: Various levels of medical centres.

Participants: Patients undergoing general anaesthesia. Interventions: PV with low tidal volume.

Primary and secondary outcome measures:

Study end points included acute lung injury (ALI), pneumonia, atelectasis, mortality, length of stay (LOS) in intensive care unit (ICU) and hospital.

Methods: Databases including PubMed, Scopus, EBSCO and EMBASE were searched from inception to May 2015. Search strategies consisted of terms related to PV and anaesthesia. We reported OR for binary outcomes including ALI, mortality, pneumonia, atelectasis and other adverse outcomes. Weighted mean difference was reported for continuous outcomes such as LOS in the ICU and hospital, pH value, partial pressure of carbon dioxide, oxygenation and duration of mechanical ventilation (MV).

Main results: A total of 22 citations were included in the systematic review and meta-analysis. PV had protective effect against the development of ALI as compared with the control group, with an OR of 0.41 $(95 \% \mathrm{Cl} 0.19$ to 0.87$)$. PV tended to be beneficial with regard to the development of pneumonia (OR 0.46 , $95 \% \mathrm{Cl} 0.16$ to 1.28$)$ and atelectasis (OR $0.68,95 \% \mathrm{Cl}$ 0.46 to 1.01 ), but statistical significance was not reached. Other adverse outcomes such as new onset arrhythmia were significantly reduced with the use of PV (OR 0.47, 95\% Cl 0.48 to 0.93 ).

Conclusions: The study demonstrates that PV can reduce the risk of $A L I$ in patients undergoing major surgery. However, there is insufficient evidence that such a beneficial effect can be translated to more clinically relevant outcomes such as mortality or duration of MV.

Trial registration number: The study was registered in PROSPERO (http://www.crd.york.ac.uk/PROSPERO/) under registration number CRD42013006416.

\section{Strengths and limitations of this study}

- This systematic review shows that protective ventilation can prevent acute lung injury in patients who underwent major surgery.

- The study was limited by the relatively small sample sizes of included studies, but the possibility of a small study effect cannot be excluded.

- The strength of the study was the use of a Bayesian approach that enhanced the reliability of the systematic review.

- There is no evidence that the use of protective ventilation is able to reduce mortality rates in patients who underwent major surgery.

\section{INTRODUCTION}

Mechanical ventilation (MV) comprises two major functions. One is to provide respiratory force to ventilate the lungs when the patient cannot breathe on his/her own; the other is to open collapsed areas of a diseased lung. A substantial number of patients with healthy lungs require MV for a variety of reasons. In the operating room, patients under general anaesthesia are incapable of breathing, and thus require MV support for respiration drive (eg, during general anaesthesia, respiratory muscle of the patient is paralysed and the respiratory drive is dependent on mechanical ventilation). In the intensive care unit (ICU), it has been reported that about $20 \%$ of patients need MV support because of neurological or neuromuscular diseases. ${ }^{1}$ In a nationwide survey involving 6469674 hospitalisations, Wunsch et $a t^{2}$ reported that among 180326 patients who received invasive MV, only $13.2 \%$ had comorbidity of pulmonary disease.

In a diseased lung, typically acute respiratory distress syndrome (ARDS), MV has been extensively studied for its proper use. The most important ventilation strategy is the 
so-called 'protective ventilation' (PV). PV comprises three components that include low tidal volume, higher positive end-expiratory pressure (PEEP) and recruitment manoeuvre. In the landmark study by Acute Respiratory Distress Syndrome Network (ARDSnet), PV with low tidal volume was found to be associated with a relative reduction in mortality rate of $22 \%(31 \%$ vs $39.8 \%$, $\mathrm{p}=0.007) .{ }^{3}$ This promising result has triggered numerous subsequent experimental and clinical studies, and PV has been repeatedly found to be beneficial for a diseased lung. ${ }^{4-6}$ In a recently updated systematic review, Petrucci and De $\mathrm{Feo}^{7}$ found that mortality can be reduced by the use of PV at day 28 and at the end of hospital stay.

It is still controversial on whether $\mathrm{PV}$ can provide a similar beneficial effect on healthy lungs. The proponents suggested that $\mathrm{PV}$ that has shown significantly reduced mortality in patients with lung injury could be extrapolated to a broader population, because the currently used clinical definition of ARDS lacks specificity that a substantial number of patients included in these trials had no diffuse alveolar damage. ${ }^{8}$ Furthermore, there is direct evidence from human trials that PV is potentially beneficial for patients with otherwise healthy lungs. ${ }^{9} 10$ However, the opponents contend that lung damage can only be induced with tidal volumes as large as twice the resting aerated compartment, and PV has no additional benefits for healthy lungs. ${ }^{11}{ }^{12}$ Recently, there have been many trials conducted to investigate the effect of PV on clinical outcomes in patients who underwent general anaesthesia, but with conflicting results. The aim of the present study was to synthesise the best evidence in this topic by systematically reviewing these studies.

\section{METHODS}

The study protocol had been registered in PROSPERO (http://www.crd.york.ac.uk/PROSPERO/) under registration number CRD42013006416, and detailed study protocol had been previously published by Zhang et al. ${ }^{13}$ We will briefly describe the method we used to conduct the systematic review.

\section{Search strategy and eligibility}

Databases including PubMed, Scopus, EBSCO and EMBASE were searched from inception to May 2015. Search strategies had been described in Zhang et al, ${ }^{13}$ and briefly it consisted terms related to PV and anaesthesia (see online supplementary file). There was no language restriction. Randomised controlled trials (RCTs) meeting the following criteria were included: (1) patients undergoing MV after induction of anaesthesia; (2) the intervention is lung PV.

\section{Data extraction}

The primary study end point was new onset acute lung injury (ALI), and secondary end points included: mortality, length of stay (LOS) in the ICU and hospital, atelectasis, pneumonia, $\mathrm{pH}$ value, partial pressure of carbon dioxide $\left(\mathrm{PaCO}_{2}\right)$, oxygenation, duration of $\mathrm{MV}$ and other adverse outcomes such as arrhythmia. Binary outcomes were analysed by extracting data on the number of events in each arm. Continuous outcomes were analysed by extracting data on respective values of that outcome in each arm. Relevant information such as demographics, tidal volume and PEEP settings in the study and control arm and use of recruitment manoeuvre was abstracted from original articles. Qualities of included RCTs were assessed by using the adapted Delphi consensus. The Delphi consensus consisted of the following eight aspects: sequence generation, allocation concealment, blinding, eligibility criteria, baseline characteristics, use of point estimates and variability, intention-to-treat analysis and sample size calculation.

LZ, LC, XZ, XH and CH contributed to data acquisition in the study, and disagreement was settled by a discussion with a third opinion.

\section{Statistical analysis}

We reported OR for binary outcomes including ALI, mortality, pneumonia, atelectasis and other adverse outcomes. Weighted mean difference (WMD) was reported for continuous outcomes such as LOS in the ICU and hospital, $\mathrm{pH}$ value, $\mathrm{PaCO}_{2}$, oxygenation and duration of MV. The primary hypothesis was that PV with low tidal volume was able to reduce postoperative complication of ALI. The effect sizes were combined by conventional method (as compared with the Bayesian approach). Owing to the heterogeneity in component studies, we used a random-effects model to pool the data. If the number of studies reporting the same end point was enough, we performed subgroup analysis to investigate the heterogeneity. Publication bias was assessed by using Begg's rank correlation test and Egger's regression test. Furthermore, a funnel plot was depicted to visually assess the symmetry. A Bayesian approach was performed by using fixed-effects and random-effects models. Posterior estimates were reported after the simulation showed convergence. Statistical software Stata V.12.0 (College Station, Texas 77845, USA) and WinBugs14 (Imperial College \& MRC, UK) were used. Two-tailed $\mathrm{p}<0.05$ was considered statistically significant.

\section{RESULTS}

Our initial search identified 125 citations from PubMed, 184 from Scopus, 166 from EBSCO and 289 from EMBASE. After a careful review by three independent reviewers, 25 studies were selected for full-text review. Three studies were excluded because two used the same cohort and one is not a real RCT, which resulted in a total of 22 citations being included for the final analysis (figure 1). ${ }^{14-35}$

Tables 1 and 2 show some important characteristics of individual component studies. In most studies, the mean 
Figure 1 Flow chart of database search and study selection.

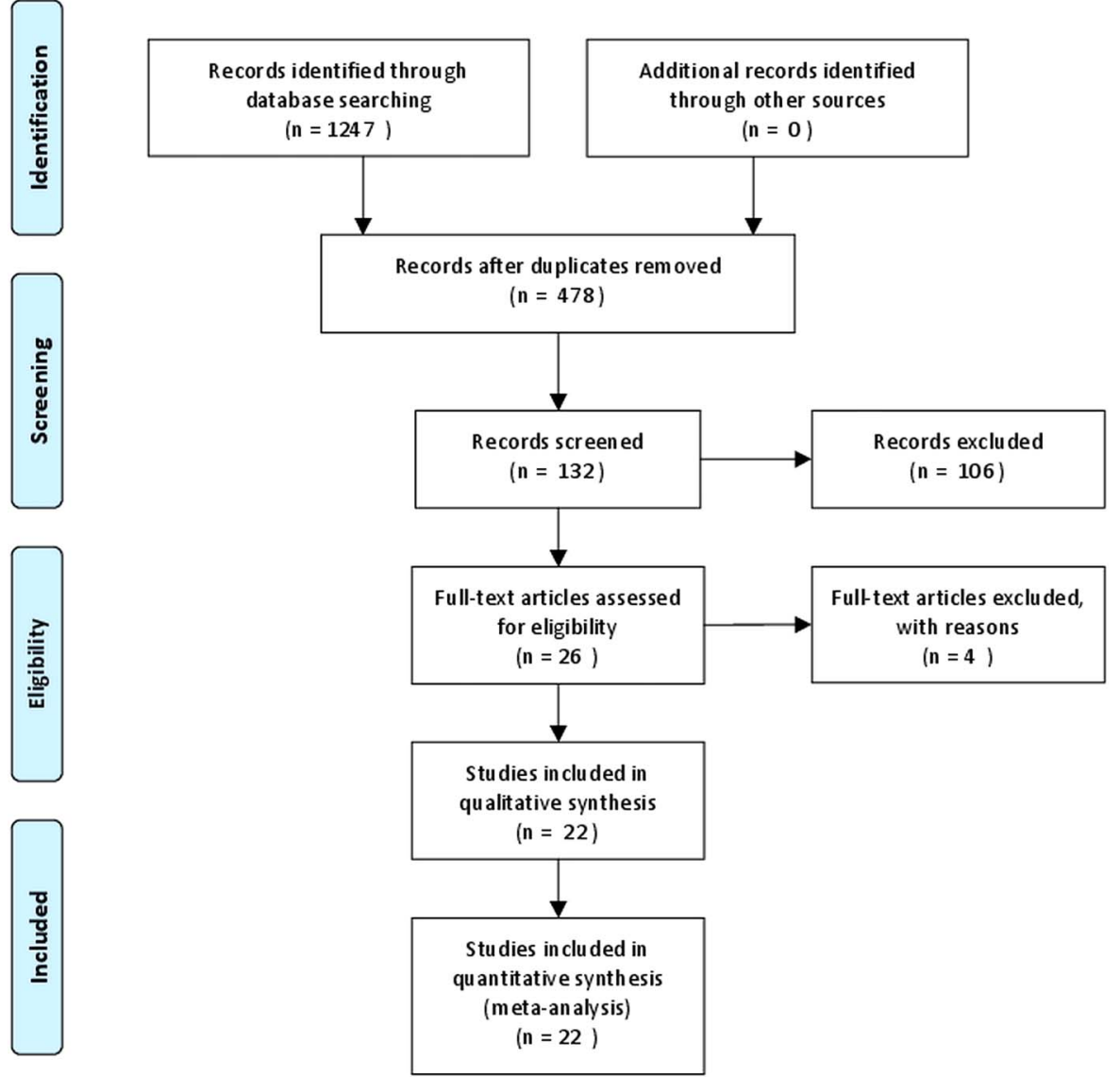

ages ranged between 50 and 70 years. However, the mean age of Cai K's study was around 20 years. The percentage of male patients varied significantly across component studies, ranging from $41 \%$ to $83 \%$. Tidal volumes in the PV group were significantly lower than in the control group, and PEEP was significantly higher in the PV group than in the control group. Risk of bias was assessed from 10 items. As shown in figure 2, all studies reported point estimate and variability for study end points. Baseline characteristics were comparable in most studies. However, the blindness to both outcome assessor and caregiver was not performed or unknown in most included studies.

Figure 3 shows the effect of PV on pulmonary and other adverse outcomes. The result showed that PV had a protective effect against the development of ALI as compared with the control group (27/507 vs 48/501), with an OR of 0.41 (95\% CI 0.19 to 0.87$)$. PV tended to be beneficial with regard to the development of pneumonia $(14 / 400$ vs $33 / 396$; OR $0.46,95 \%$ CI 0.16 to $1.28)$ and atelectasis $(81 / 497$ vs $101 / 492$; OR $0.68,95 \%$ CI 0.46 to 1.01), but statistical significance was not reached. Other adverse outcomes such as new onset arrhythmia were significantly reduced with the use of $\mathrm{PV}$ $(82 / 473$ vs $109 / 466$; OR 0.47 , $95 \%$ CI 0.48 to 0.93$)$. Figure 4 shows the pooled effects of respiratory parameters. PV resulted in significantly increased oxygenation (WMD=17.79, 95\% CI 7.99 to $27.60 \mathrm{~mm} \mathrm{Hg}$ ), but at the expense of carbon dioxide retention (WMD 2.87,
95\% CI 2.25 to $3.49 \mathrm{~mm} \mathrm{Hg}$ ). Owing to significantly elevated $\mathrm{PaCO}_{2}$, arterial $\mathrm{pH}$ value was reduced in the $\mathrm{PV}$ group (WMD $-0.02,95 \%$ CI -0.03 to -0.02 ). However, the alveolar-arterial gradient was not significantly different between the two groups (WMD -20.39 , 95\% CI -45.32 to 4.55 ), most probably due to the limited number of studies being combined. With respect to other clinical outcomes, only the length of hospital stay could be marginally but statistically significantly shortened with the PV strategy (WMD $-0.95,95 \%$ CI -1.29 to -0.61 days). However, there was no evidence that PV could reduce the mortality, LOS in the ICU and the duration of MV (figure 5). A funnel plot was used to assess the publication bias. We arbitrarily selected two outcomes for this purpose (eg, ALI and $\mathrm{PaCO}_{2}$ ). The figure 6 shows some potential publication bias. Furthermore, Egger's test showed $\mathrm{p}=0.006$ for ALI and $\mathrm{p}=0.027$ for $\mathrm{PaCO}_{2}$, both indicating significant bias.

\section{Bayesian approach}

Bayesian approaches with random-effects and fixed-effects models were used to synthesise data. For the primary outcome ALI, both random-effects and fixed-effects Bayesian approaches obtained results (OR $0.40,95 \%$ Crl $0.105-0.927$ for a random-effects model; OR $0.49,95 \%$ Crl $0.29-0.83$ for a fixed-effects model) in agreement with that obtained by the classical method. For pneumonia, only the fixed-effects Bayesian approach showed a statistically significantly improved outcome 


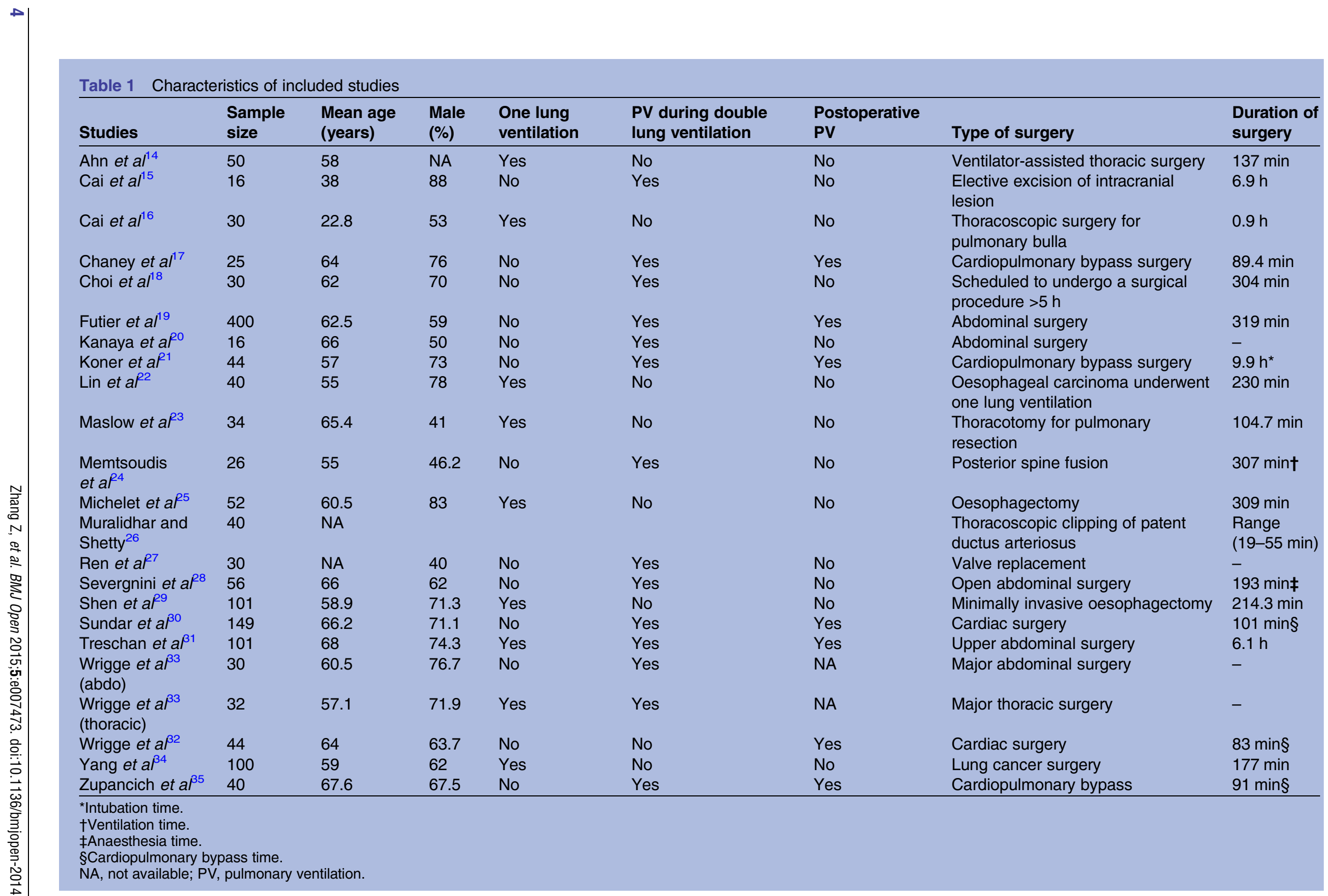


Table 2 Comparisons of ventilator settings between treatment and control groups

\begin{tabular}{|c|c|c|c|c|c|c|c|c|c|c|c|c|c|c|c|c|}
\hline \multirow[b]{2}{*}{ Studies } & \multicolumn{8}{|c|}{ Treatment (protective ventilation group) } & \multicolumn{8}{|c|}{ Control } \\
\hline & $\begin{array}{l}\text { Mode } \\
\text { of MV } \\
\text { (treatment) }\end{array}$ & $\begin{array}{l}\text { Preset TV } \\
\text { (treatment) }\end{array}$ & $\begin{array}{l}\text { Actual TV } \\
\text { (treatment) }\end{array}$ & $\begin{array}{l}\text { Preset } \\
\text { PEEP } \\
\text { (treatment) }\end{array}$ & $\begin{array}{l}\text { Actual } \\
\text { PEEP } \\
\text { (treatment) }\end{array}$ & $\begin{array}{l}\text { Lung } \\
\text { recruit- } \\
\text { ment }\end{array}$ & $\begin{array}{l}\text { Respirat- } \\
\text { ory rate }\end{array}$ & $\begin{array}{l}\text { Minute } \\
\text { ventilation }\end{array}$ & $\begin{array}{l}\text { Mode } \\
\text { of MV }\end{array}$ & $\begin{array}{l}\text { Preset TV } \\
\text { (treatment) }\end{array}$ & $\begin{array}{l}\text { Actual TV } \\
\text { (treatment) }\end{array}$ & $\begin{array}{l}\text { Preset } \\
\text { PEEP } \\
\text { (treatment) }\end{array}$ & $\begin{array}{l}\text { Actual } \\
\text { PEEP } \\
\text { (treatment) }\end{array}$ & $\begin{array}{l}\text { Lung } \\
\text { recruit- } \\
\text { ment }\end{array}$ & $\begin{array}{l}\text { Respirat- } \\
\text { ory rate }\end{array}$ & $\begin{array}{l}\text { Minute } \\
\text { ventilation }\end{array}$ \\
\hline Ahn et $a l^{14}$ & & 6 & & 5 & & No & & & & 10 & & 0 & & No & & \\
\hline Cai et $a l^{15}$ & & 6 & & 0 & & No & & & & 10 & & 0 & & No & & \\
\hline Cai et $a l^{16}$ & & $3-5$ & & NA & & No & & & & $8-10$ & & NA & & No & & \\
\hline $\begin{array}{l}\text { Chaney } \\
\text { et } a l^{17}\end{array}$ & & 6 & & 5 & & No & 16 & & VCV & 12 & & 5 & & No & 8 & \\
\hline Choi et $a l^{18}$ & & 6 & & 10 & & No & & & & 12 & & 0 & & No & & \\
\hline Futier et $a l^{19}$ & VCV & $6-8$ & 6.4 & $6-8$ & 6 & Yes & & & & $10-12$ & 11.1 & 0 & 0 & No & & \\
\hline $\begin{array}{l}\text { Kanaya } \\
\text { et } a^{P^{0}} \\
\text { Koner O } \\
\text { et } a^{P^{1}}\end{array}$ & & 7 & & 1 & & No & & & & 10 & & 1 & & No & & \\
\hline Lin et $a^{22}$ & & $5-6$ & 5.4 & $3-5$ & & No & 13 & & & 10 & 9.4 & 0 & & No & 11 & \\
\hline $\begin{array}{l}\text { Maslow } \\
\text { et } a f^{3}\end{array}$ & & 5 & & 5 & & No & 14 & & & 10 & & 0 & & No & 7 & \\
\hline $\begin{array}{l}\text { Memtsoudis } \\
\text { et } a R^{4}\end{array}$ & VCV & 6 & & 8 & & No & 12 & & VCV & 12 & & 0 & & No & 8 & \\
\hline $\begin{array}{l}\text { Michelet } \\
\text { et } a P^{5} \\
\text { Muralidhar } \\
\text { and Shetty } \\
\text { Ren et } a^{R^{7}}\end{array}$ & & 5 & & 5 & & No & 15 & & & 9 & & 0 & & No & 12 & \\
\hline $\begin{array}{l}\text { Severgnini } \\
\text { et } a^{88}\end{array}$ & VCV & 7 & 7.7 & 10 & & Yes & 12.8 & & & 9 & 9.5 & 0 & & No & 11 & \\
\hline Shen et $a$ f9 $^{2}$ & & 5 & & 5 & & No & & & PRVC & 8 & & 0 & & No & & \\
\hline $\begin{array}{l}\text { Sundar } \\
\text { et } a \beta^{\beta 0}\end{array}$ & & 6 & 6.2 & 5 & 5 & No & 17.6 & 7.2 & & 10 & 10 & 5 & 4.9 & No & 12.6 & 8.1 \\
\hline $\begin{array}{l}\text { Treschan } \\
\text { et } a \beta^{\beta 1}\end{array}$ & PRVC & 6 & 6.7 & 5 & & & 17 & 7.8 & & 12 & 12 & 5 & & No & 8 & 6.2 \\
\hline $\begin{array}{l}\text { Wrigge } \\
\text { et } a \beta^{\beta 3} \text { (abdo) }\end{array}$ & & 6 & & 10 & & & 16 & 9.5 & & $12-15$ & & 0 & & & 6 & 9.2 \\
\hline $\begin{array}{l}\text { Wrigge } \\
\text { et } a \beta^{\beta 3} \\
\text { (thoracic) }\end{array}$ & & 6 & & 10 & & & 16 & 10 & VC & $12-15$ & & 0 & & & 8 & 8.5 \\
\hline $\begin{array}{l}\text { Wrigge } \\
\text { et } a^{\beta 2}\end{array}$ & & 6 & & ARDS-net & 9 & No & 21 & & & 12 & & ARDS-net & 7 & No & 10 & \\
\hline Yang et $a \beta^{34}$ & $\mathrm{PC}$ & 6 & & 5 & 4.8 & No & 12.8 & & & 10 & & 0 & 1 & No & 9.4 & \\
\hline $\begin{array}{l}\text { Zupancich } \\
\text { et } a \beta^{35}\end{array}$ & & 8 & 6.8 & 10 & 9.1 & No & & 8.1 & & $10-12$ & 10.9 & $2-3$ & 2.1 & No & & 12.2 \\
\hline
\end{tabular}

Cells left blank were those not reported in the original studies.

ARDS, acute respiratory distress syndrome; MV, mechanical ventilation; NA, not available; PC, pressure control; PEEP, positive end-expiratory pressure; PRVC, pressure-regulated volume control; TV, tidal volume; VCV, volume control ventilation. 


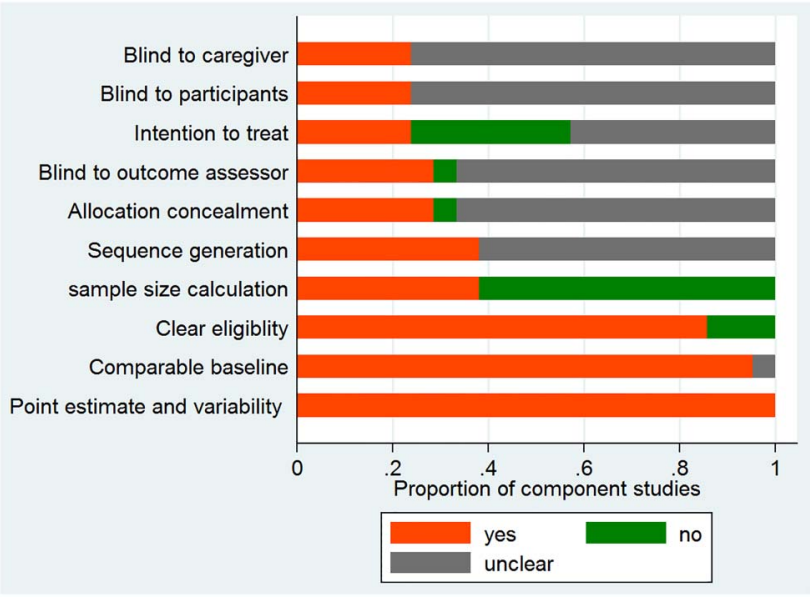

Figure 2 Risk of bias for included component studies assessed from items of blindness, sequence generation, allocation concealment, sample size calculation, clear definition of eligibility criteria, comparability of baseline characteristics, intention to treat analysis and use of point estimate and variability. The $\mathrm{x}$ axis is scaled to represent the proportion of component studies with either item of 'yes', 'no' or 'unclear'.

with PV (OR 0.40, 95\% Crl 0.21-0.74). The result of a random-effects Bayesian approach was in agreement with the classical approach. The three approaches arrived at the same result with respect to mortality. The interpretation of the results obtained by the Bayesian approach was more straightforward for subject matter audience. For instance, the result of ALI can be interpreted as follows: there is a $95 \%$ probability of the true OR being somewhere between 0.29 and 0.83 .

\section{DISCUSSION}

This systematic review shows that PV can protect against the development of ALI in patients who underwent major surgery, and the result remains robust by using the Bayesian approach. However, there is no evidence that PV can protect from the development of pneumonia and atelectasis in this group of patients. PV treatment is able to improve oxygenation, but at the expense of mild carbon dioxide retention. With respect to other clinical outcomes, there is a slightly shortened LOS in hospital.

The result that PV reduces the risk of postoperative ALI is in line with that reported by Serpa Neto et al. ${ }^{36} \mathrm{In}$ Neto's study, there is a substantial number of observational studies that are subjective to more bias. We found that the largest observational study contributed more than half of the total population, and it reported a more beneficial effect of PV on ALI prevention than other
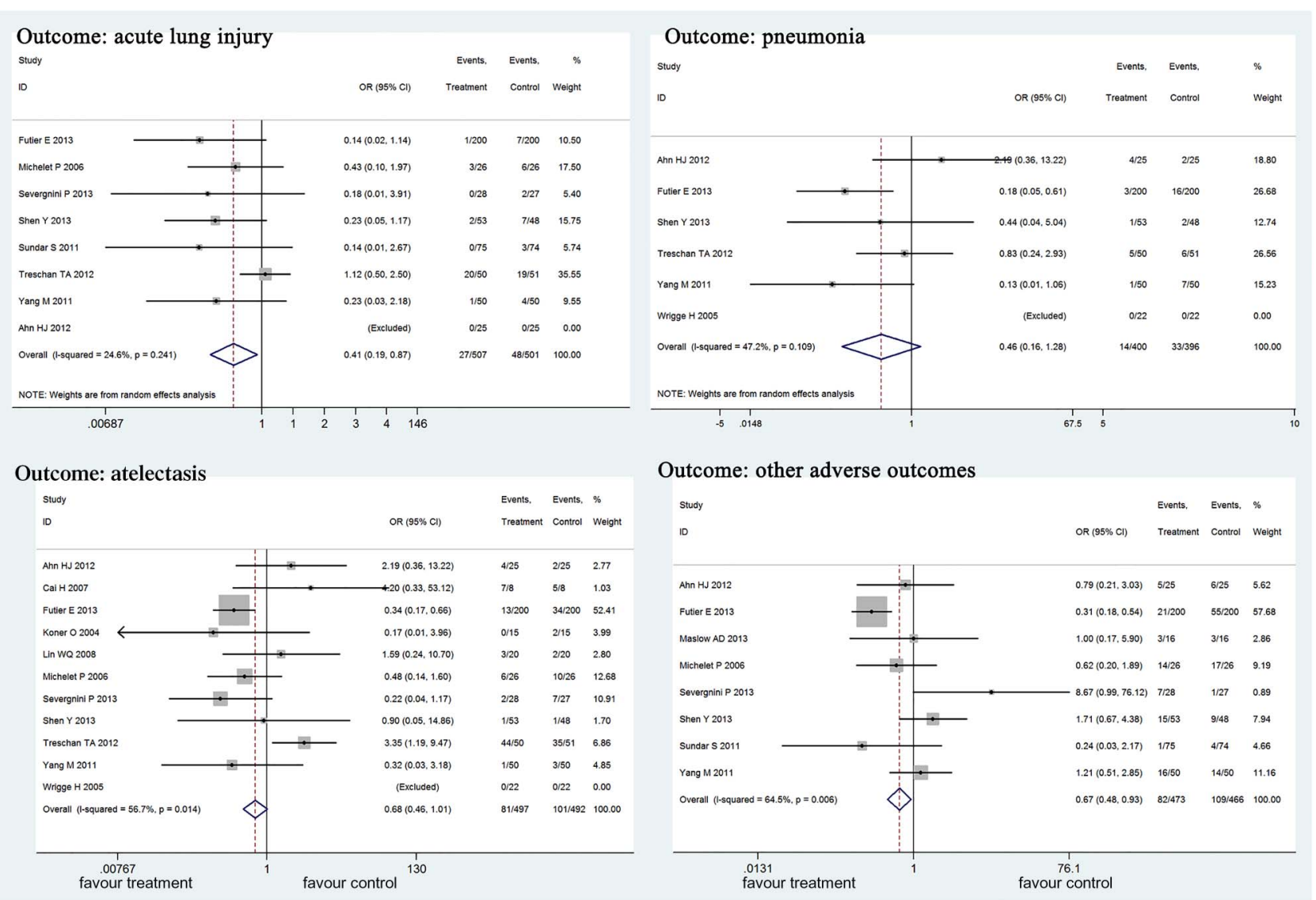

Figure 3 Forest plots showing the effect of protective ventilation on outcomes of new onset acute lung injury (ALI), pneumonia, atelectasis and other adverse outcomes. The results show that protective ventilation is protective against new onset ALI (OR $0.41,95 \% \mathrm{Cl} 0.19$ to 0.87 ) and other adverse outcomes (OR $0.67,95 \% \mathrm{Cl} 0.48$ to 0.93 ). The protective ventilation tends to reduce the risk of pneumonia and atelectasis, but statistical significance is not reached. 


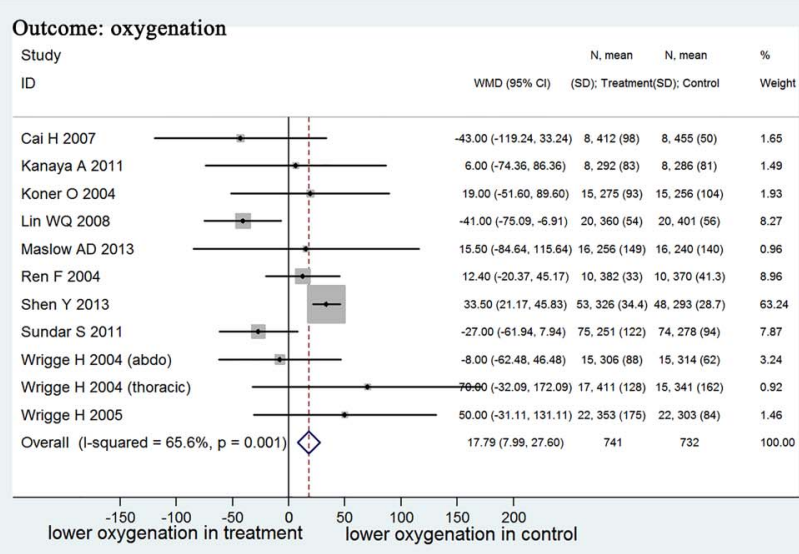

Outcome: Alveolar-arterial gradient

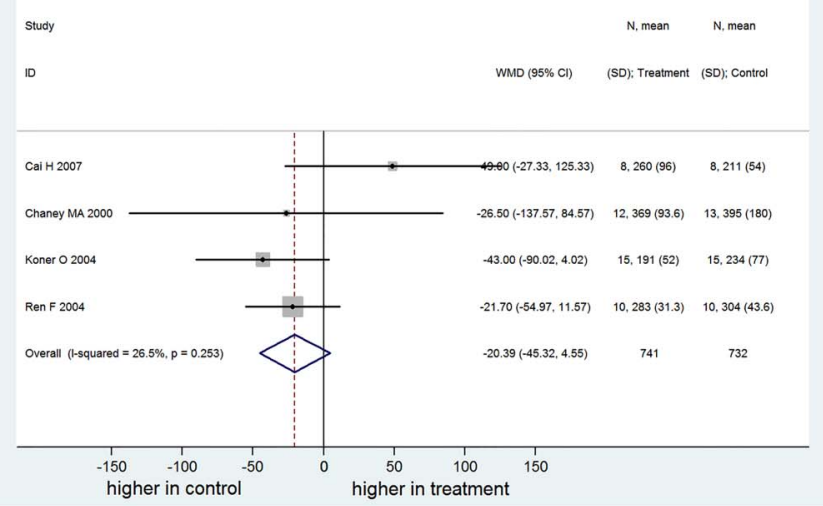

Outcome: partial pressure of arterial carbon dioxide

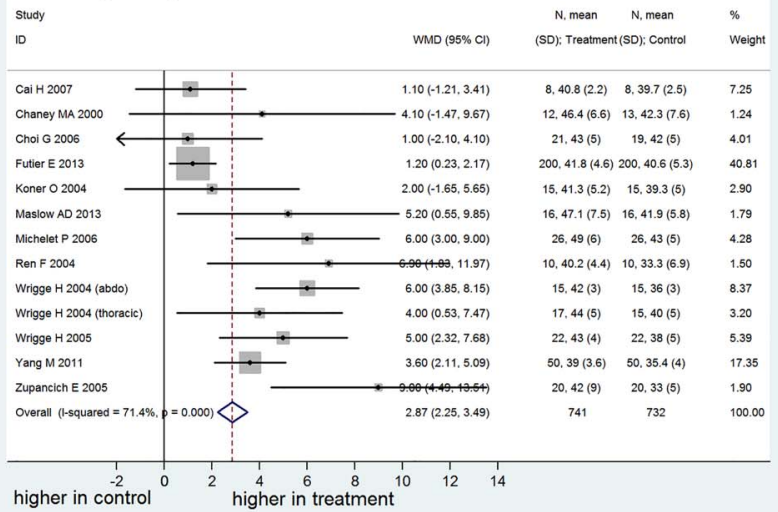

Outcome: arterial $\mathrm{pH}$ value

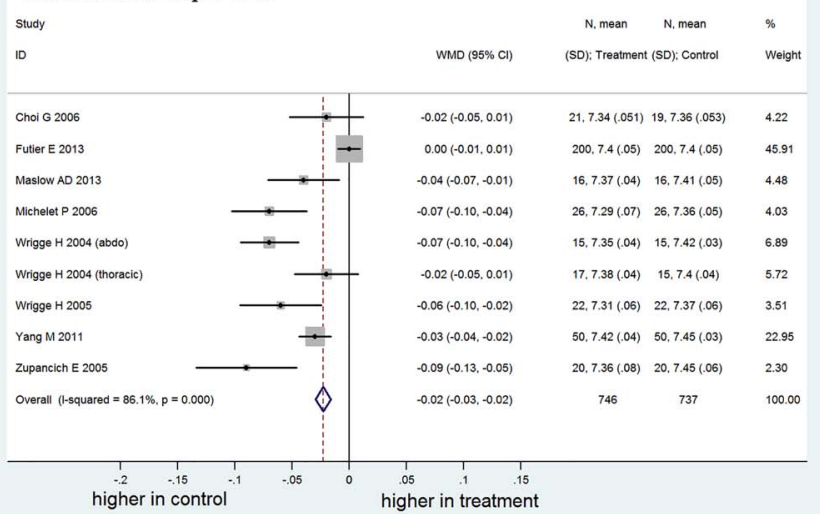

Figure 4 Comparison of respiratory parameters between treatment and control groups. Protective ventilation induces higher oxygenation as compared with the control group (weighted mean difference (WMD) $17.79 \mathrm{~mm} \mathrm{Hg}, 95 \% \mathrm{Cl} 7.99$ to $27.60 \mathrm{~mm} \mathrm{Hg}$ ), but it results in more carbon dioxide retention (WMD 2.87, 95\% 2.25 to $3.49 \mathrm{~mm} \mathrm{Hg}$ ). Alveolar-arterial oxygen gradient is not significantly different between groups. Finally, a lower $\mathrm{pH}$ value is found in the protective ventilation group (WMD $-0.02,95 \%$ -0.03 to $-0.02 \mathrm{~mm} \mathrm{Hg}$ ), which is consistent with the carbon dioxide retention.

smaller RCTs. ${ }^{9}$ With respect to mortality, while our study failed to identify any beneficial effect of PV, Neto's study found that it had a beneficial effect. However, the beneficial effect disappeared after excluding observational studies in sensitivity analysis, which was in agreement with our results. The same study group performed another individual patient data meta-analysis in this topic, and the result was consistent with our findings. ${ }^{37}$ However, the study included a smaller number of component studies than our study, probably due to the unavailability of individual patient data.

Atelectasis is an important complication of general anaesthesia in major surgery. ${ }^{38}$ Three underlying mechanisms have been proposed as contributors to the atelectasis: compression atelectasis, absorption atelectasis and loss of surfactant atelectasis. ${ }^{39}{ }^{40}$ General anaesthesia can cause alterations in chest wall mechanics. With reduced wall motion during anaesthesia, atelectasis is likely to develop in the gravity-dependent region of the lung. ${ }^{41}$ Other factors contributing to atelectasis include a reluctance to cough after the operation, prolonged intraoperative recumbent position and postoperative diaphragm dysfunction. The use of perioperative PV may be potentially protective against atelectasis, and our systematic review was designed to test this hypothesis. However, we failed to identify any beneficial effect of the $\mathrm{PV}$ on postoperative atelectasis. In the result, there is a trend towards a more beneficial effect on the PV arm, but statistical significance was not reached at the predefined level of 0.05 . This could be the result of the small sample size in component trials, and the lack of statistical power. The PROVHILO trial has recently been published and it recruited more homogeneous patients and had higher statistical power. ${ }^{42}$ However, this trial also failed to identify any beneficial effect of high PEEP ventilation on postoperative pulmonary complications. Probably, tidal volume plays a pivotal role in preventing pulmonary complications and the study did not vary tidal volumes between the intervention and control arms. ${ }^{43}$

Since PV primarily incorporates low tidal volume ventilation (figure 2), it is not surprising that it may result in carbon dioxide retention and ensuing hypercapnia. In our systematic review, $\mathrm{PV}$ was associated with significantly increased arterial $\mathrm{PaCO}_{2}$ (WMD 2.87, 95\% CI 2.25 to $3.49 \mathrm{~mm} \mathrm{Hg}$ ) and reduction in $\mathrm{pH}$ value (WMD -0.02 , $95 \%$ CI -0.03 to -0.02 ). However, this alteration is minimal as compared with the notion of "permissive hypercapnia' used during PV for patients with ARDS. 

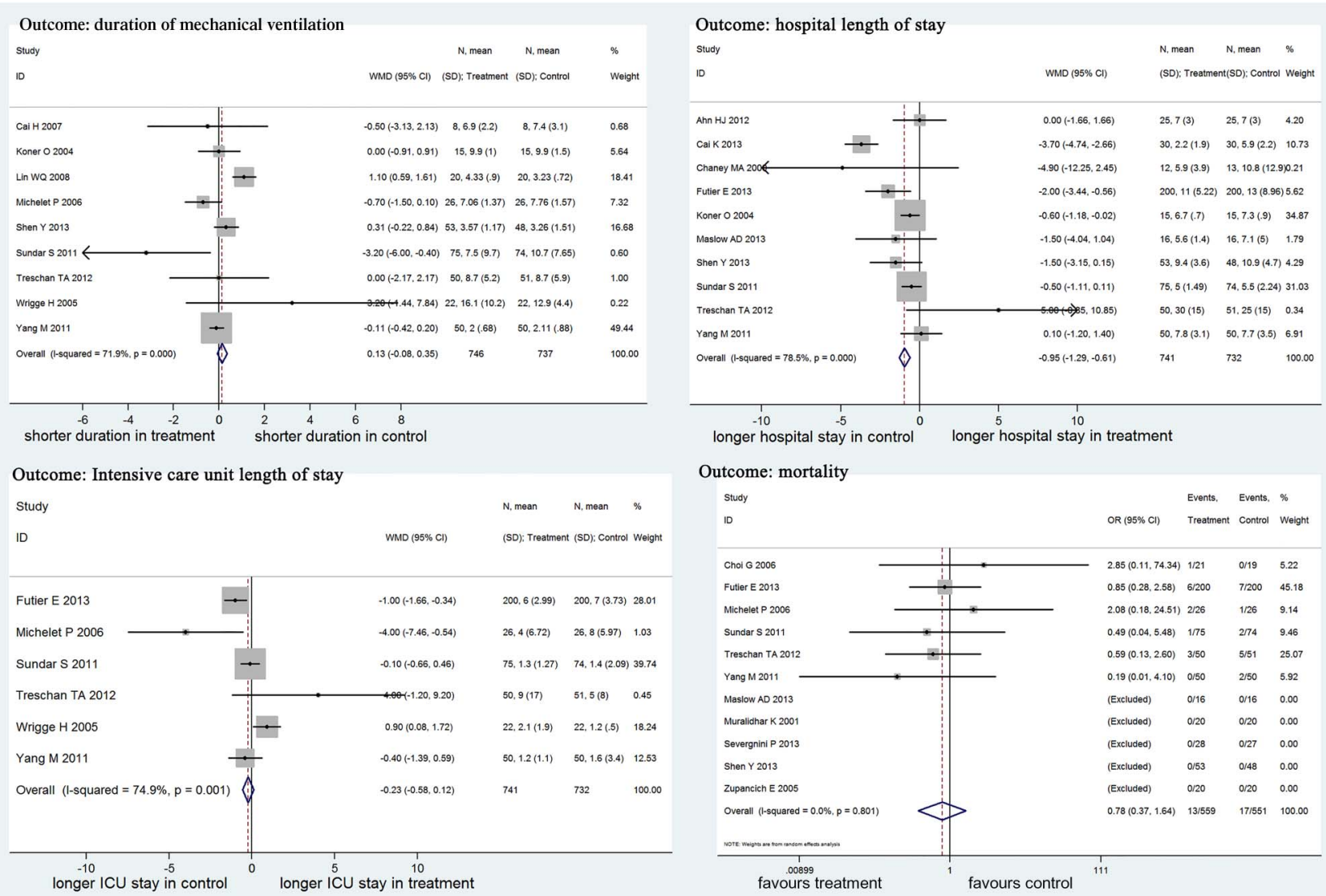

Figure 5 Effect of protective ventilation on clinical outcomes. As shown in the figure, protective ventilation can significantly reduce the length of stay in hospital by 1 day as compared with conventional ventilation (weighted mean difference (WMD) $-0.95,95 \% \mathrm{Cl}-1.29$ to -0.61 days). However, there is no evidence that protective ventilation can reduce the duration of mechanical ventilation, length of stay in the intensive care unit (ICU) and mortality rate.

Since the effect of hypercapnia on clinical outcome is not harmful, ${ }^{44} \mathrm{PV}$ induced minimal increase in $\mathrm{PaCO}_{2}$ retention is less likely to be harmful in patients who underwent general anaesthesia. Conversely, there are a few evidences supporting that hypercapnic acidosis is protective against tissue damage during inflammatory response. ${ }^{45-47}$ Another finding in the study is that PV had a beneficial effect on improving oxygenation.
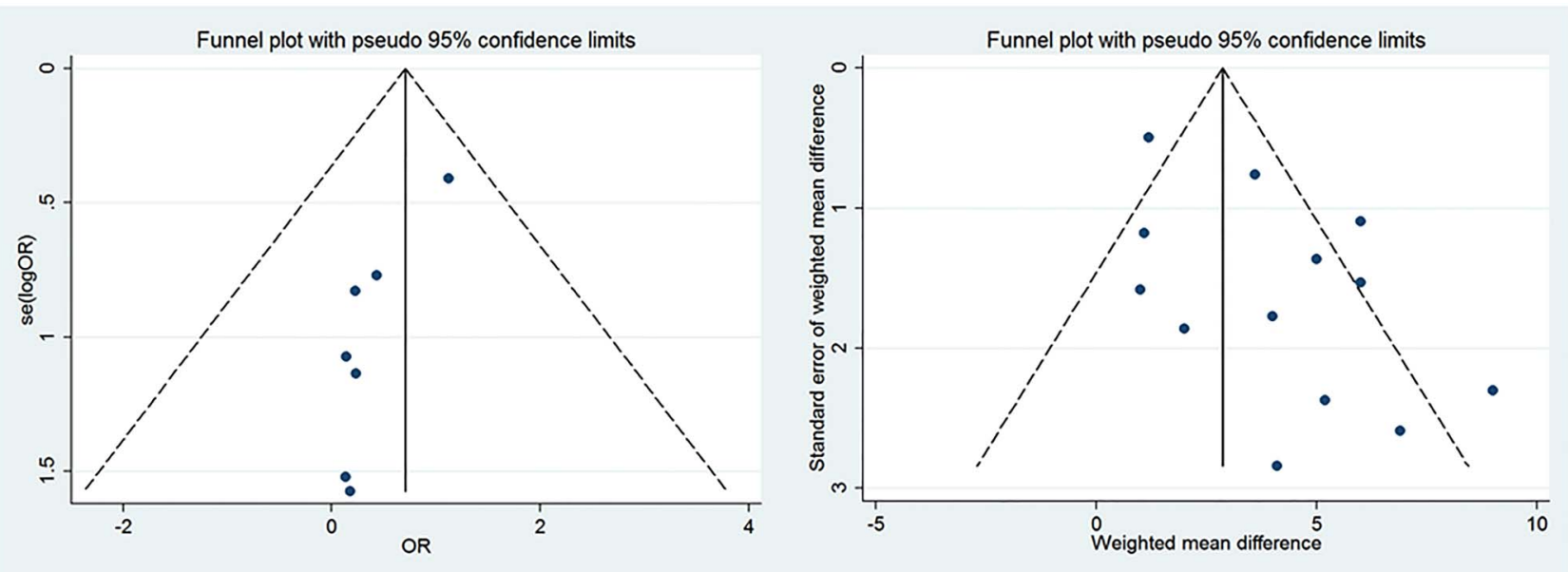

Figure 6 Publication bias assessed by funnel plot. Publication bias was assessed using the effect sizes of OR of acute lung injury and weighted mean difference of carbon dioxide retention. The result showed that there was potential publication bias in the present analysis as represented by the asymmetrical appearance of both plots. Egger's tests were statistically significant for both parameters $(\mathrm{p}=0.006$ and 0.027 , respectively). 
However, this may be of limited clinical significance because most patients who underwent elective general anaesthesia have preserved respiratory function. This is in contrast to the situation encountered in the management of patients with ARDS when hypoxaemia is the major clinical problem.

The strength of the systematic review is the incorporation of the Bayesian approach. It is common that trials included in meta-analysis are usually small in sample size, and the systematic review is not an exception. Small studies when combined with a classical approach are subject to the so-called small study effect. ${ }^{48}$ The classical approach to meta-analysis of trials is to assume that the summary statistics have a normal likelihood, which however may not hold true when a trial is small. The Bayesian approach overcomes this issue by providing a unified modelling framework. ${ }^{49}$ Fortunately, the sensitivity analysis shows that the Bayesian approach does not significantly alter the result obtained with the classical method. Furthermore, the median or mean value and associated credible interval obtained from posterior distribution obtained via iteration can be more directly interpreted. For instance, we obtained an OR of 0.41 (95\% CI 0.19 to 0.87 ) for the risk of ALI. The common interpretation of this result is: there is a $95 \%$ probability of the true OR being somewhere between 0.19 and 0.87 . However, this is a misunderstanding of the classic or frequentist approach and is actually the interpretation from the Bayesian perspective. The correct interpretation should be: if repeated samples were taken and the 95\% CI computed for each sample, $95 \%$ of the intervals would contain the population mean. This rather convoluted language prohibits the probabilities that clinicians are seeking for. In this sense, the Bayesian approach provides a more comprehensible $95 \%$ credible interval for subject matter audience. ${ }^{50}$

In conclusion, the systematic review demonstrates that PV can reduce the risk of ALI development in patients who underwent major surgery. However, there is insufficient evidence that such beneficial effect can be translated to more clinically relevant outcomes such as mortality, LOS in the ICU or duration of MV. Owing to the significant number of observational studies being conducted in this field, further data synthesis can be performed by incorporating evidence from observational studies as the prior distribution. In this way, the importance of the prior information can be discounted by using a series of powers as we have already done in another study. ${ }^{51}$

\footnotetext{
Author affiliations

${ }^{1}$ Department of Critical Care Medicine, Jinhua Municipal Central Hospital, Jinhua Hospital of Zhejiang University, Jinhua, Zhejiang, People's Republic of China

${ }^{2}$ Department of Medical ICU, Peking Union Medical College Hospital, Beijing, People's Republic of China

${ }^{3}$ Department of Emergency, Jinhua Municipal Central Hospital, Jinhua Hospital of Zhejiang University, Jinhua, Zhejiang, People's Republic of China ${ }^{4}$ Department of Critical Care Medicine, Zhejiang Hospital, Hangzhou, Zhejiang, People's Republic of China
}

Contributors BD conceived the idea and designed the study. ZZ performed statistical analysis and drafted the manuscript. LZ, LC and XZ (both Xia Zhang and Xiuqi Zhu) collected the data and helped with statistical analysis, and LC and $\mathrm{XH}$ helped to extract data and review the manuscript. $\mathrm{CH}$ helped in data acquisition and result interpretation during revision. $\mathrm{BD}$ and $\mathrm{ZZ}$ are identified as the guarantors of the paper, taking responsibility for the integrity of the work as a whole, from inception to published article.

Funding ZZ received a grant from the Science and Technology Research plan of Jinhua city (2012-3-031). CH received grants from the Zhejiang traditional Chinese medicine research project (Program: No. 2011ZZ001), the Zhejiang medical and health science and technology project (Program:

N0.2013KYB004), and the Hall of Zhejiang province science and technology intensive medical technology innovation team research project (Program: No.2011R50018-02).

Competing interests None declared.

Provenance and peer review Not commissioned; externally peer reviewed.

Data sharing statement Additional data can be accessed via the Dryad data repository at http://datadryad.org/ with the doi:10.5061/dryad.8679n.

Open Access This is an Open Access article distributed in accordance with the Creative Commons Attribution Non Commercial (CC BY-NC 4.0) license, which permits others to distribute, remix, adapt, build upon this work noncommercially, and license their derivative works on different terms, provided the original work is properly cited and the use is non-commercial. See: http:// creativecommons.org/licenses/by-nc/4.0/

\section{REFERENCES}

1. Esteban A, Frutos-Vivar F, Muriel A, et al. Evolution of mortality over time in patients receiving mechanical ventilation. Am J Respir Crit Care Med 2013;188:220-30.

2. Wunsch H, Linde-Zwirble WT, Angus DC, et al. The epidemiology of mechanical ventilation use in the United States. Crit Care Med 2010;38:1947-53.

3. [No authors listed]. Ventilation with lower tidal volumes as compared with traditional tidal volumes for acute lung injury and the acute respiratory distress syndrome. The Acute Respiratory Distress Syndrome Network. N Engl J Med 2000;342:1301-8.

4. Villar J, Kacmarek RM, Perez-Mendez L, et al. A high positive end-expiratory pressure, low tidal volume ventilatory strategy improves outcome in persistent acute respiratory distress syndrome: a randomized, controlled trial. Crit Care Med 2006;34:1311-18.

5. Sperber J, Lipcsey M, Larsson A, et al. Lung protective ventilation induces immunotolerance and nitric oxide metabolites in porcine experimental postoperative sepsis. PLOS ONE 2013;8:e83182.

6. Wolthuis EK, Choi G, Dessing MC, et al. Mechanical ventilation with lower tidal volumes and positive end-expiratory pressure prevents pulmonary inflammation in patients without preexisting lung injury. Anesthesiology 2008;108:46-54.

7. Petrucci N, De Feo C. Lung protective ventilation strategy for the acute respiratory distress syndrome. Cochrane Database Syst Rev 2013;(2):CD003844.

8. Ferguson ND. Low tidal volumes for all? JAMA 2012;308:1689-90.

9. Licker M, Diaper J, Villiger $Y$, et al. Impact of intraoperative lung-protective interventions in patients undergoing lung cancer surgery. Crit Care 2009;13:R41.

10. Yilmaz M, Keegan MT, Iscimen R, et al. Toward the prevention of acute lung injury: protocol-guided limitation of large tidal volume ventilation and inappropriate transfusion. Crit Care Med 2007;35:1660-6; quiz 7.

11. Marini JJ. Lower tidal volumes for everyone: principle or prescription? Intensive Care Med 2013;39:3-5.

12. Protti $A$, Cressoni $M$, Santini $A$, et al. Lung stress and strain during mechanical ventilation: any safe threshold? Am J Respir Crit Care Med 2011;183:1354-62.

13. Zhang $Z$, Hu X, Zhang $X$, et al. Lung protective ventilation in patients undergoing major surgery: a systematic review protocol. BMJ Open 2014;4:e004542.

14. Ahn HJ, Kim JA, Yang M, et al. Comparison between conventional and protective one-lung ventilation for ventilator-assisted thoracic surgery. Anaesth Intensive Care 2012;40:780-8.

15. Cai $\mathrm{H}$, Gong $\mathrm{H}$, Zhang $\mathrm{L}$, et al. Effect of low tidal volume ventilation on atelectasis in patients during general anesthesia: a computed tomographic scan. J Clin Anesth 2007;19:125-9. 
16. Cai $\mathrm{K}$, Wang $\mathrm{X}, \mathrm{Ye} \mathrm{J}$, et al. [Laryngeal mask anesthesia in video-assisted thoracoscopic surgery for pulmonary bulla: comparison with intubation anesthesia]. Nan Fang Yi Ke Da Xue Xue Bao 2013;33:756-60.

17. Chaney MA, Nikolov MP, Blakeman BP, et al. Protective ventilation attenuates postoperative pulmonary dysfunction in patients undergoing cardiopulmonary bypass. J Cardiothorac Vasc Anesth 2000;14:514-18.

18. Choi G, Wolthuis EK, Bresser $P$, et al. Mechanical ventilation with lower tidal volumes and positive end-expiratory pressure prevents alveolar coagulation in patients without lung injury. Anesthesiology 2006;105:689-95.

19. Futier E, Constantin JM, Paugam-Burtz C, et al. A trial of intraoperative low-tidal-volume ventilation in abdominal surgery. N Engl J Med 2013;369:428-37.

20. Kanaya A, Satoh D, Kurosawa S. [Influence of tidal volume on functional residual capacity during general anesthesia]. Masui 2011;60:1149-52

21. Koner O, Celebi S, Balci $\mathrm{H}$, et al. Effects of protective and conventional mechanical ventilation on pulmonary function and systemic cytokine release after cardiopulmonary bypass. Intensive Care Med 2004;30:620-6.

22. Lin WQ, Lu XY, Cao LH, et al. [Effects of the lung protective ventilatory strategy on proinflammatory cytokine release during one-lung ventilation]. Ai Zheng 2008;27:870-3.

23. Maslow AD, Stafford TS, Davignon KR, et al. A randomized comparison of different ventilator strategies during thoracotomy for pulmonary resection. J Thorac Cardiovasc Surg 2013;146:38-44.

24. Memtsoudis SG, Bombardieri AM, Ma Y, et al. The effect of low versus high tidal volume ventilation on inflammatory markers in healthy individuals undergoing posterior spine fusion in the prone position: a randomized controlled trial. $J$ Clin Anesth 2012;24:263-9.

25. Michelet $\mathrm{P}, \mathrm{D}$ 'Journo $\mathrm{XB}$, Roch $\mathrm{A}$, et al. Protective ventilation influences systemic inflammation after esophagectomy: a randomized controlled study. Anesthesiology 2006;105:911-19.

26. Muralidhar K, Shetty DP. Ventilation strategy for video-assisted thoracoscopic clipping of patent ductus arteriosus in children. Paediatr Anaesth 2001;11:45-8.

27. Ren F, Cai HW, Jiao HN. [Effects of different mechanical ventilation methods on oxygenation and shunt fraction in patients undergoing valve replacement]. Zhong Nan Da Xue Xue Bao Yi Xue Ban 2004;29:583-5.

28. Severgnini P, Selmo G, Lanza C, et al. Protective mechanical ventilation during general anesthesia for open abdominal surgery improves postoperative pulmonary function. Anesthesiology 2013;118:1307-21.

29. Shen $\mathrm{Y}$, Zhong $\mathrm{M}$, Wu W, et al. The impact of tidal volume on pulmonary complications following minimally invasive esophagectomy: a randomized and controlled study. $J$ Thorac Cardiovasc Surg 2013;146:1267-73; discussion 73-4.

30. Sundar S, Novack V, Jervis K, et al. Influence of low tidal volume ventilation on time to extubation in cardiac surgical patients. Anesthesiology 2011;114:1102-10.

31. Treschan TA, Kaisers W, Schaefer MS, et al. Ventilation with low tidal volumes during upper abdominal surgery does not improve postoperative lung function. $\mathrm{Br} J$ Anaesth 2012;109:263-71.

32. Wrigge $\mathrm{H}$, Uhlig $\mathrm{U}$, Baumgarten $\mathrm{G}$, et al. Mechanical ventilation strategies and inflammatory responses to cardiac surgery: a prospective randomized clinical trial. Intensive Care Med 2005;31:1379-87.

33. Wrigge $\mathrm{H}$, Uhlig $\mathrm{U}$, Zinserling J, et al. The effects of different ventilatory settings on pulmonary and systemic inflammatory responses during major surgery. Anesth Analg 2004;98:775-81, table of contents.

34. Yang M, Ahn HJ, Kim K, et al. Does a protective ventilation strategy reduce the risk of pulmonary complications after lung cancer surgery? A randomized controlled trial. Chest 2011;139: 530-7.

35. Zupancich E, Paparella D, Turani F, et al. Mechanical ventilation affects inflammatory mediators in patients undergoing cardiopulmonary bypass for cardiac surgery: a randomized clinical trial. J Thorac Cardiovasc Surg 2005;130:378-83.

36. Serpa Neto A, Cardoso SO, Manetta JA, et al. Association between use of lung-protective ventilation with lower tidal volumes and clinical outcomes among patients without acute respiratory distress syndrome: a meta-analysis. JAMA 2012;308:1651-9.

37. Serpa Neto A, Hemmes SN, Barbas CS, et al. Protective versus conventional ventilation for surgery: a systematic review and individual patient data meta-analysis. Anesthesiology 2015.

38. O'Brien J. Absorption atelectasis: incidence and clinical implications. AANA J 2013;81:205-8.

39. Joyce $\mathrm{CJ}$, Williams AB. Kinetics of absorption atelectasis during anesthesia: a mathematical model. J Appl Physiol 1999;86: 1116-25.

40. Hedenstierna G, Rothen HU. Respiratory function during anesthesia: effects on gas exchange. Compr Physiol 2012;2:69-96.

41. Ward DS, Karan SB, Pandit JJ. Hypoxia: developments in basic science, physiology and clinical studies. Anaesthesia 2011;66(Suppl 2):19-26.

42. Hemmes SN, Severgnini P, Jaber S, et al. Rationale and study design of PROVHILO-a worldwide multicenter randomized controlled trial on protective ventilation during general anesthesia for open abdominal surgery. Trials 2011;12:111.

43. Hemmes SN, Gama de Abreu M, Pelosi P, et al. PROVE Network Investigators for the Clinical Trial Network of the European Society of Anaesthesiology. High versus low positive end-expiratory pressure during general anaesthesia for open abdominal surgery (PROVHILO trial): a multicentre randomised controlled trial. Lancet 2014;384:495-503.

44. Curley G, Hayes M, Laffey JG. Can 'permissive' hypercapnia modulate the severity of sepsis-induced ALI/ARDS? Crit Care 2011;15:212.

45. Laffey JG, Tanaka M, Engelberts D, et al. Therapeutic hypercapnia reduces pulmonary and systemic injury following in vivo lung reperfusion. Am J Respir Crit Care Med 2000;162:2287-94.

46. Sinclair SE, Kregenow DA, Lamm WJ, et al. Hypercapnic acidosis is protective in an in vivo model of ventilator-induced lung injury. $A m \mathrm{~J}$ Respir Crit Care Med 2002;166:403-8.

47. Takeshita K, Suzuki Y, Nishio K, et al. Hypercapnic acidosis attenuates endotoxin-induced nuclear factor-[kappa]B activation. $\mathrm{Am}$ $J$ Respir Cell Mol Biol 2003;29:124-32.

48. Zhang Z, Xu X, Ni H. Small studies may overestimate the effect sizes in critical care meta-analyses: a meta-epidemiological study. Crit Care 2013;17:R2.

49. Warn DE, Thompson SG, Spiegelhalter DJ. Bayesian random effects meta-analysis of trials with binary outcomes: methods for the absolute risk difference and relative risk scales. Stat Med 2002;21:1601-23.

50. Kalil AC, Sun J. Why are clinicians not embracing the results from pivotal clinical trials in severe sepsis? A Bayesian analysis. PLoS ONE 2008;3:e2291.

51. Zhang $Z$. The efficacy of activated protein $C$ for the treatment of sepsis: incorporating observational evidence with a Bayesian approach. BMJ Open 2015;5:e006524. 